\title{
Cardiac self-efficacy and quality of life in patients with coronary heart disease: a cross-sectional study from Palestine
}

\author{
Aya Barham ${ }^{1}$, Reem Ibraheem ${ }^{1}$ and Sa'ed H. Zyoud ${ }^{2,3,4^{*}}$ (D)
}

\begin{abstract}
Background: Psychological factors, such as self-efficacy, are important in understanding the progress and management of coronary heart disease (CHD), and how patients make lifestyle modifications to compensate for the disease. The main objectives of this research are to assess patterns of cardiac self-efficacy (CSE) and quality of life (QoL) among CHD patients, and to determine the factors that affect their QoL.

Methods: A cross-sectional descriptive correlational study was carried out between August 2016 and December 2016. We used a structured questionnaire completed by interviewers during face-to-face interviews with patients. Cardiac self-efficacy was evaluated using three scales: 1) the 5-item perceived efficacy in patient- physician interaction scale (PEPPI-5); 2) the self-efficacy for managing chronic diseases 6-item scale (SEMCD-6) and 3) Sullivan's cardiac self-efficacy scale 13-items (SCSES). The 5-level version of the EuroQoL 5-dimensions questionnaire (EQ-5D-5 $\mathrm{L}$ ), and Euroqol Visual Analogue Scale (EQ VAS) were used to evaluate health-related QoL (HRQoL) among CHD patients. Multiple binary logistic regression was carried out to evaluate the influence on the QoL score of demographic and medical characteristics, and self-efficacy factors.

Results: A total of 275 patients participated in our study. The patients' mean age was $59.51 \pm 1.005$ years. The HRQoL was measured by the EQ-5D-5 L index score and EQ-VAS score; their means were $0.62 \pm 0.16$ and $57.44 \pm$ 1.61, respectively. The QoL showed moderate positive correlations with the PEPPI-5 $(r=0.419 ; p$-value $<0.001)$, SEMCD-6 $(r=0.419 ; p$-value $<0.001)$, and SCSES score $(r=0.273 ; p$-value $<0.001)$. Multiple binary logistic regression showed that only patients with higher PEPPI-5 score (odds ratio $(\mathrm{OR})=1.11 ; 95 \%$ confidence interval $(\mathrm{Cl})=1.01-1.22$; $p=0.036)$, and higher SCSES score $(\mathrm{OR}=1.10 ; 95 \% \mathrm{Cl}=1.03-1.17 ; p=0.004)$ were significantly associated with a high QoL score. Moreover, multiple binary logistic regression model showed that patients with higher numbers of medications ( $\mathrm{OR}=0.23 ; 95 \% \mathrm{Cl}=0.07-0.78) ; p=0.018$ ) remained significantly associated with impaired QoL.
\end{abstract}

Conclusions: Lower levels of self-efficacy and poorer patient-physician interactions predicted poor HRQoL. Thus, health providers should be aware of these factors in CHD patients when trying to improve their QoL.

Keywords: Cardiac self-efficacy, Quality of life, Coronary heart disease, Palestine

\footnotetext{
*Correspondence: saedzyoud@yahoo.com; saedzyoud@najah.edu

${ }^{2}$ Poison Control and Drug Information Center (PCDIC), College of Medicine and Health Sciences, An-Najah National University, Nablus 44839, Palestine ${ }^{3}$ Department of Clinical and Community Pharmacy, College of Medicine and Health Sciences, An-Najah National University, Nablus 44839, Palestine Full list of author information is available at the end of the article
}

(c) The Author(s). 2019 Open Access This article is distributed under the terms of the Creative Commons Attribution 4.0 International License (http://creativecommons.org/licenses/by/4.0/), which permits unrestricted use, distribution, and reproduction in any medium, provided you give appropriate credit to the original author(s) and the source, provide a link to the Creative Commons license, and indicate if changes were made. The Creative Commons Public Domain Dedication waiver (http://creativecommons.org/publicdomain/zero/1.0/) applies to the data made available in this article, unless otherwise stated. 


\section{Background}

Coronary heart disease (CHD) results from atherosclerotic changes of the coronary artery. Hypertension, diabetes mellitus, obesity, smoking and an aggressive response to stress are well-known major risk factors for the development of CHD [1]. In most countries, CHD is considered to be one of the important causes of global morbidity and mortality and is a major economic burden. In developed countries, the mortality rate due to CHD has recently decreased; however, the morbidity rate has increased $[2,3]$.

In the occupied Palestinian territory, cardiovascular diseases are one of the main causes of morbidity and mortality. They are the first leading cause of death in Palestine, as reported by the Palestinian Ministry of Health in 2010, accounting for approximately $25 \%$ of all deaths, followed by cerebrovascular diseases (12\%), cancer (11\%) and diabetes (6\%) [4]. Coronary heart disease was the cause of approximately $2.3 \%$ of all reported deaths in Palestine in 2014; most deaths due to CHD occur above the age of 65 years. Coronary heart disease is the main cause of death among other cardiovascular diseases in Palestine, accounting for about $36.1 \%$ of all cardiovascular deaths in the West Bank in 2014 [5]. A study of CHD conducted in Jerusalem in 1997, in the Palestinian and Jewish population, showed that the rate of CHD in Palestinian women was 2.4 times more than that in Jewish women, and the rate in Palestinian men was 1.6 times more than that in Jewish men [6].

In addition to cardiac physiology, psychological factors are important in understanding the progress and management of any chronic disease, and how new lifestyle modifications can compensate for the disease. Psychological factors, for example, anxiety and cardiac self-efficacy (CSE), may affect the development of chronic diseases through both psychological distress and patient behaviours. Cardiac self-efficacy is defined as a cardiac-specific measure of a patient's confidence in his or her capacity to carry out activities which may be affected by symptoms and complications of their cardiovascular disease [7].

Because of illness manifestations following CHD, the health-related quality of life (HRQoL) could be harmed. The World Health Organization describes quality of life (QoL) as “... individual's realisation of his/her position in life in the context of the prevailing culture and beliefs and in relation to his/her goals and concerns" [8]. In modern medicine, QoL is as a predictor of general wellbeing that is an important outcome in the treatment of any chronic disease. Outcomes of treatment of any chronic disease are not merely predicted by the frequency and severity of the disease, but also by how this treatment will affect the patient's QoL and general wellbeing. Quality of life in CHD patients is affected by many factors such as gender, social support, personality, socioeconomic factors, psychological symptoms (e.g. depression and anxiety), angina, and dyspnoea [9].
There is no doubt that chronic diseases has an important and adverse effect on QoL, and it is well known that improvement in it is the final and an important goal of family medicine [10]. Till now, there is a lot of physicians who focus merely on the physical aspect of diseases, despite its importance, it is not the only aspect to care of; a good doctor is the one who helps the patient to achieve a better QoL, in terms of physical, psychological, mental and social life. Family medicine focuses on several ways for improvement in QoL. An important way for achieving this is by engorging patients to participate in decision making in issues that relate to their health and disease management, when the patient understands the disease and the best way to deal with it, this will capable him/ her to live with the disease and try to minimize its adverse effects on him/ her life. A holistic approach to the patient's physical and psychosocial well-being, a focus on the family, an emphasis on QoL, and continuity of care are main principles that make the family physician exclusively appropriate to care for chronically ill patients, as patientcentered indices of quality $[11,12]$.

Our purposes in this research are to assess patterns of CSE and QoL among CHD patients, and to determine the factors associated with QoL. This research is necessary because: (1) it concerns CHD, a highly prevalent disease with a high mortality rate, (2) understanding the onset, treatment and progress of CHD is achieved by CSE, QoL and life style modifications, (3) in family medicine, the concept of self-efficacy has extended far beyond being merely a psychological issue to an important concept that will affect patients' behaviours in the treatment of chronic diseases; that is, for example, how strictly he or she will adhere to the medication schedule, eat a healthy diet, and avoid a sedentary lifestyle, (4) self-efficacy is a modifiable characteristic; many behaviours and life style modifications have been shown to improve a patient's self-efficacy. Consequently, the findings of this study will benefit society, considering that CSE plays an important role in improving QoL in CHD patients. Thus, family physicians can achieve a high health status of their patients by applying the recommended approach deduced from the results of this study, and (5) until now, no studies have been conducted in Palestine of the effect of CSE on QoL in CHD patients.

\section{Methods}

\section{Study design}

A cross-sectional descriptive correlational study was conducted between August 2016 and December 2016. Inpatients with CHD were recruited from the Al-Watani Hospital and Al-Najah National University Hospital, both located in Nablus city in the occupied Palestinian territories. We chose to examine CHD for two reasons. Firstly, the management of $\mathrm{CHD}$ is a multidisciplinary issue and 
Table 1 Socio-demographic and clinical characteristics of the study sample

\begin{tabular}{|c|c|}
\hline Variable & $\begin{array}{l}\text { Frequency } \\
N=275\end{array}$ \\
\hline \multicolumn{2}{|l|}{ Age (year) } \\
\hline$<48$ & $28(10.2)$ \\
\hline $48-57$ & $77(28.0)$ \\
\hline $58-67$ & $114(41.5)$ \\
\hline $68-77$ & $43(15.6)$ \\
\hline$\geq 78$ & $13(4.7)$ \\
\hline \multicolumn{2}{|l|}{ Gender } \\
\hline Female & $121(44.0)$ \\
\hline Male & $154(56.0)$ \\
\hline \multicolumn{2}{|l|}{ Residency } \\
\hline City & $108(39.3)$ \\
\hline Village & 135(49.1) \\
\hline Palestinian refugee camps & $32(11.6)$ \\
\hline \multicolumn{2}{|l|}{ Social status } \\
\hline Married & 198(72.0) \\
\hline Single, widowed, divorced & $77(28.0)$ \\
\hline \multicolumn{2}{|l|}{ Educational level } \\
\hline No Formal & $66(24.0)$ \\
\hline Primary & $106(38.5)$ \\
\hline Secondary & $60(21.8)$ \\
\hline University & 43(15.6) \\
\hline \multicolumn{2}{|l|}{ Occupation } \\
\hline Employed & 129(46.9) \\
\hline Unemployed & $146(53.1)$ \\
\hline \multicolumn{2}{|l|}{ Income (NIS) } \\
\hline Moderate to High & $116(42.2)$ \\
\hline Low & 159(57.8) \\
\hline \multicolumn{2}{|l|}{ BMI } \\
\hline Normal & 49(17.8) \\
\hline Overweight & 129(46.9) \\
\hline Obese & 97(35.3) \\
\hline \multicolumn{2}{|l|}{ Cigarette } \\
\hline Not smoker & 144(52.4) \\
\hline Light & $7(2.5)$ \\
\hline Moderate & $36(13.1)$ \\
\hline Heavy & $13(4.7)$ \\
\hline Ex-smoker & $75(27.3)$ \\
\hline \multicolumn{2}{|l|}{ Duration of the disease (year) } \\
\hline$\leq 3$ & $139(50.5)$ \\
\hline $4-5$ & $71(25.8)$ \\
\hline$>5$ & $65(23.6)$ \\
\hline \multicolumn{2}{|l|}{ Total number of medications } \\
\hline $1-3$ & $81(29.5)$ \\
\hline
\end{tabular}

Table 1 Socio-demographic and clinical characteristics of the study sample (Continued)

\begin{tabular}{ll}
\hline Variable & $\begin{array}{l}\text { Frequency (\%) } \\
N=275\end{array}$ \\
\hline $4-6$ & $161(58.5)$ \\
$\geq 7$ & $33(12.0)$ \\
Total number of chronic diseases & \\
0 & $13(4.7)$ \\
1 & $38(13.8)$ \\
2 & $84(30.5)$ \\
3 & $73(26.5)$ \\
$\geq 4$ & $67(24.4)$ \\
\hline EQ-5D European Quality of Life scale 5 dimensions, EQ-VAS European Quality \\
of Life visual analogue scale, NIS New Israeli Shekel, BMI body mass index
\end{tabular}

includes not only a commitment to taking the prescribed drugs, but also to make lifestyle changes to cope with this chronic disease. Secondly, in the setting of many chronic diseases, higher self-efficacy has been linked to better management. We aimed to detect the relationship between CSE and QoL.

\section{Participants and setting}

The required sample size was estimated at 275 patients. We included patients who: 1 ) were aged $\geq 18$ years; 2 ) had a history of ischaemic heart disease; 3 ) had a history of coronary revascularisation; 4) had no history of myocardial infarction in the previous 6 months; 5 ) were permanently resident in Nablus; 6) agreed to participate in the study. We excluded patients who had acute and serious conditions that would affect their QoL or make them unable to participate in completing the interview, such as stroke, uncompensated heart failure, a body mass index $(\mathrm{BMI})>40$, psychological problems, amputated limbs or receiving chemotherapy.

\section{Sampling procedure and sample size calculation}

According to the American Heart Association, the total CHD prevalence was $6.4 \%$ in the United States in adults older than 20 years of age [13]. In addition, a previous study by Kark et al. [6] found that the incidence of coronary events among Palestinians in Jerusalem was $0.34 \%$. Another study in Kerala, South India found that the prevalence of CHD was $7.4 \%$ for rural Kerala and $11 \%$ for urban Kerala [14]. Another study by Suwatanaviroj and Yamwong [15] found that the prevalence of definite CHD in Thai Muslims was $14.20 \%$, which was significantly higher than the prevalence in Thai Buddhists (6.2\%). Furthermore, projections from 2013 estimates show that the prevalence of CHD will increase by nearly $18 \%$ by 2030 [16]. Thus, we took the highest percentage into consideration and, using the Raosoft sample size calculator: (http://www.raosoft.com/samplesize.html), an 


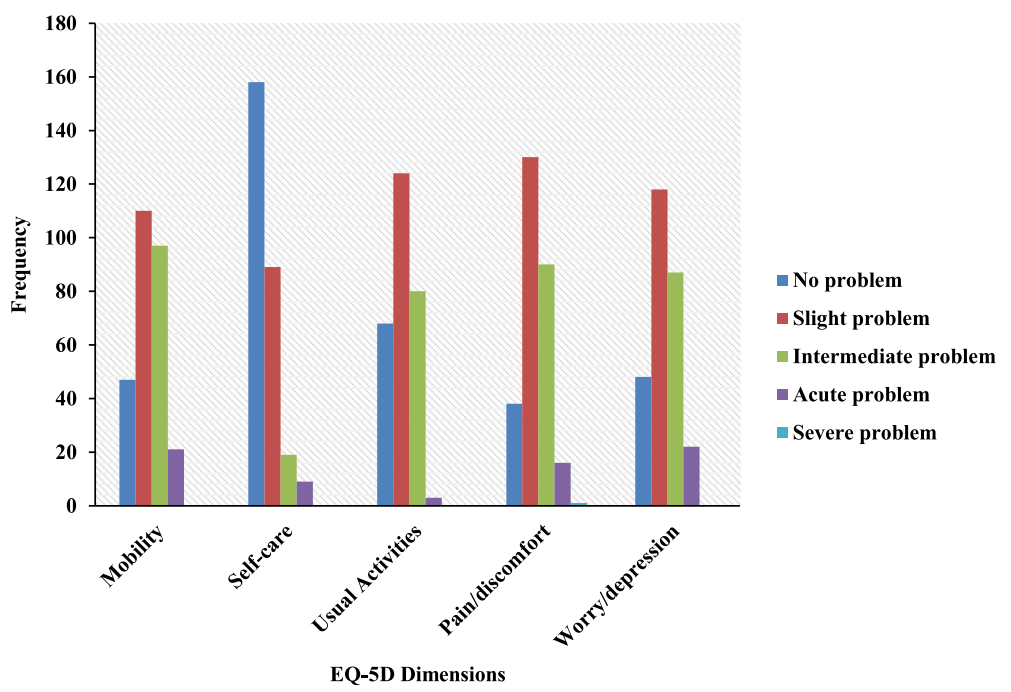

Fig. 1 Distribution of health-related quality of life measures in different European quality of life scale 5 (EQ-5D) dimensions

automated software program, the number of 225 was reached. In addition, another 5 to $10 \%$ was added in an attempt to minimise errors and increase the study's reliability as much as possible. In the current study, 275 CHD patients were included. A convenience sample of participant was recruited.

\section{Data collection instrument}

The data collection instruments contained four sections.

The first section gathered socio-demographic data which were provided by participants, such as age $(<48$, $48-57,58-67,68-77$, or $\geq 78$ ), gender (male or female), residence (city, village, or Palestinian refugee camp), marital status (married, single, widowed, or divorced), educational level (no formal, primary or secondary school, or university), occupation (employed or unemployed), income (moderate to high or low), and height and weight information. We calculated the BMI of each participant using the Excel program (defined as "weight in kilograms divided by height in metres squared") and categorised this into underweight $(<18.50)$, normal $(18.50-24.99)$, overweight $(\geq 25.00)$, and obese $(\geq 30.00)[6]$.

- The second section recorded clinical CHDassociated data, such as duration of the illness in years $(\leq 3,4-5$, or $\geq 5)$, total number of medications (1-3, 4-6, or $\geq 7)$, the number of associated chronic morbid conditions $(0,1,2,3$, or $\geq 4)$, and smoking (none, light, moderate, heavy, or ex-smoker).

- The third section concerned CSE, which was evaluated using three scales: 1) the 5-item perceived efficacy in patient-physician interaction scale (PEPPI-5). The PEPPI-5 includes five items; each item starts with "how confident are you in your ability to..? " Items are rated by participants from one to five; $1=$ "not at all confident", 5 = "very confident". The totalled results are in the range of 5 to 25 ; higher scores indicate that the participant has higher self-efficacy in patient-physician interactions [17]. 2) The self-efficacy for managing chronic disease 6-item scale (SEMCD-6) consists of six items, each starting with "How confident are you that you can...?" Participants rated each item on a 10-point scale; 1 = "not at all confident ", 10 = "totally confident". Total scores of this scale are totalled to range from 6 to 60 , with higher scores representing higher perceived self-efficacy for managing chronic diseases [18]. 3) Sullivan's cardiac self-efficacy scale 13-items (SCSES); this was originally written in English and put through the standard process of translation into Arabic and back-translation into English by independent bilingual translators to assess its translational validity. Sullivan et al. developed the SCSES, which consists of 13 items, each starting with: "how confident are you that you know or can ...' '. Items are rated by participants from 0 to $4: 0=$ "not at all confident", $4=$ "completely confident". This scale contains two dimensions: control symptoms (8 questions) and maintaining functioning (5 questions) [19].

- The last section was related to QoL: we used the 5-level version of the EuroQoL 5-dimensions questionnaire (EQ-5D-5 L), and Euroqol Visual Analogue Scale (EQVAS). The EQ-5D-5 $\mathrm{L}$ is designed to collect information related to QoL from five health domains: self-care, mobility, usual activity, anxiety/depression, and pain/discomfort. Each aspect of these domains was evaluated in terms of no/slight/moderate/severe/extreme problems. The EQ-VAS asks the participant to rate his/her overall health by marking an $\mathrm{X}$ on a scale from 0 to 100 [20]. 
Table 2 EQ-5D total score by socio-demographic and clinical variables

\begin{tabular}{|c|c|c|c|c|}
\hline Variable & $\begin{array}{l}\text { Total } \\
\text { Frequency (\%) or median [Q1-Q3] } \\
N=275\end{array}$ & $\begin{array}{l}\text { Patients with better HRQoL } \\
\text { Frequency (\%) or median [Q1-Q3] } \\
n=140\end{array}$ & $\begin{array}{l}\text { Patients with worse HRQoL } \\
\text { Frequency (\%) or median [Q1-Q3] } \\
n=135\end{array}$ & $p$-value ${ }^{a}$ \\
\hline \multicolumn{5}{|l|}{ Age (year) } \\
\hline$<48$ & $28(10.2)$ & $21(15.0)$ & $7(5.2)$ & \multirow[t]{5}{*}{$0.025^{b}$} \\
\hline $48-57$ & $77(28.0)$ & 43(30.7) & $34(25.2)$ & \\
\hline $58-67$ & $114(41.5)$ & 54(38.6) & $60(44.4)$ & \\
\hline $68-77$ & 43(15.6) & 16(11.4) & $27(20.0)$ & \\
\hline$\geq 78$ & $13(4.7)$ & $6(4.3)$ & $7(5.2)$ & \\
\hline \multicolumn{5}{|l|}{ Gender } \\
\hline Female & $121(44.0)$ & $56(40.0)$ & $65(48.1)$ & \multirow[t]{2}{*}{$0.174^{b}$} \\
\hline Male & 154(56.0) & $84(60.0)$ & $70(51.9)$ & \\
\hline \multicolumn{5}{|l|}{ Residency } \\
\hline City & $108(39.3)$ & $54(38.6)$ & $54(40.0)$ & \multirow[t]{3}{*}{$0.820^{b}$} \\
\hline Village & 135(49.1) & $71(50.7)$ & $64(47.4)$ & \\
\hline Palestinian refugee camps & $32(11.6)$ & 15(10.7) & 17(12.6) & \\
\hline \multicolumn{5}{|l|}{ Social status } \\
\hline Married & 198(72.0) & 103(73.6) & $95(70.4)$ & \multirow[t]{2}{*}{$0.554^{b}$} \\
\hline Single, widowed, divorced & $77(28.0)$ & $37(26.4)$ & 40(29.6) & \\
\hline \multicolumn{5}{|l|}{ Educational level } \\
\hline No formal & $66(24.0)$ & $28(20.0)$ & $38(28.1)$ & \multirow[t]{4}{*}{$0.181^{b}$} \\
\hline Primary & $106(38.5)$ & $52(37.1)$ & $54(40.0)$ & \\
\hline Secondary & $60(21.8)$ & $33(23.6)$ & $27(20.0)$ & \\
\hline University & 43(15.6) & 27(19.3) & 16(11.9) & \\
\hline \multicolumn{5}{|l|}{ Occupation } \\
\hline Employed & 129(46.9) & $77(55.0)$ & $52(38.5)$ & \multirow[t]{2}{*}{$0.006^{b}$} \\
\hline Unemployed & $146(53.1)$ & 63(45.0) & $83(61.5)$ & \\
\hline \multicolumn{5}{|l|}{ Income (NIS) } \\
\hline Moderate to high & $116(42.2)$ & $67(47.9)$ & 49(36.3) & \multirow[t]{2}{*}{$0.052^{b}$} \\
\hline Low & 159(57.8) & $73(52.1)$ & $86(63.7)$ & \\
\hline \multicolumn{5}{|l|}{ BMI } \\
\hline Normal & $49(17.8)$ & $27(19.3)$ & $22(16.3)$ & \multirow[t]{3}{*}{$0.390^{b}$} \\
\hline Overweight & 129(46.9) & $69(49.3)$ & $60(44.4)$ & \\
\hline Obese & $97(35.3)$ & $44(31.4)$ & $53(39.3)$ & \\
\hline \multicolumn{5}{|l|}{ Cigarette } \\
\hline Not smoker & 144(52.4) & $79(56.4)$ & $65(48.1)$ & \multirow[t]{5}{*}{$0.541^{b}$} \\
\hline Light & $7(2.5)$ & $4(2.9)$ & $3(2.2)$ & \\
\hline Moderate & $36(13.1)$ & 18(12.9) & 18(13.3) & \\
\hline Heavy & $13(4.7)$ & $7(5.0)$ & $6(4.4)$ & \\
\hline Ex-smoker & $75(27.3)$ & $32(22.9)$ & 43(31.9) & \\
\hline \multicolumn{5}{|l|}{ Duration of the disease (year) } \\
\hline$\leq 3$ & $139(50.5)$ & $82(58.6)$ & $57(42.2)$ & \multirow[t]{3}{*}{$0.025^{b}$} \\
\hline $4-5$ & $71(25.8)$ & $31(22.1)$ & 40(29.6) & \\
\hline$>5$ & $65(23.6)$ & 27(19.3) & $38(28.1)$ & \\
\hline \multicolumn{5}{|l|}{ Total number of medications } \\
\hline $1-3$ & $81(29.5)$ & 25(18.5) & $56(40.0)$ & $<0.001^{b}$ \\
\hline
\end{tabular}


Table 2 EQ-5D total score by socio-demographic and clinical variables (Continued)

\begin{tabular}{|c|c|c|c|c|}
\hline Variable & $\begin{array}{l}\text { Total } \\
\text { Frequency (\%) or median [Q1-Q3] } \\
N=275\end{array}$ & $\begin{array}{l}\text { Patients with better HRQoL } \\
\text { Frequency (\%) or median [Q1-Q3] } \\
n=140\end{array}$ & $\begin{array}{l}\text { Patients with worse HRQoL } \\
\text { Frequency (\%) or median [Q1-Q3] } \\
n=135\end{array}$ & $p$-value ${ }^{a}$ \\
\hline $4-6$ & $161(58.5)$ & $87(64.4)$ & $74(52.9)$ & \\
\hline$\geq 7$ & $33(12.0)$ & 23(17.0) & $10(7.1)$ & \\
\hline \multicolumn{5}{|c|}{ Total number of chronic diseases } \\
\hline 0 & $13(4.7)$ & $3(2.2)$ & $10(7.1)$ & \multirow[t]{5}{*}{$<0.001^{b}$} \\
\hline 1 & $38(13.8)$ & $9(6.7)$ & $29(20.7)$ & \\
\hline 2 & $84(30.5)$ & $44(32.6)$ & $40(28.6)$ & \\
\hline 3 & $73(26.5)$ & $34(25.2)$ & $39(27.9)$ & \\
\hline$\geq 4$ & $67(24.4)$ & $45(33.3)$ & $22(15.7)$ & \\
\hline PEPPI-5 & $17[15-20]$ & $18[16-20]$ & $16[13-8]$ & $<0.001^{c}$ \\
\hline SEMCD-6 & $5.8[5-6.8]$ & $6.3[5.4-7.3]$ & $5.5[4.7-6.5]$ & $<0.001^{c}$ \\
\hline SCSES & $34[29-38]$ & $37[31-40]$ & $31[26-36]$ & $<0.001^{c}$ \\
\hline
\end{tabular}

The EuroQol Group offered the Arabic version of the EQ-5D by online registration (ID: 15871). The EQ-5D score was calculated using the UK value set [21] due to the lack of a Palestinian or regional value set at the time of this study; this value set was the most commonly used in Palestine [22-25]. We performed a pilot study on 15 patients to test the feasibility and clarity of the questions. The patients participating in the pilot study were not included in the final analysis. Trained medical students, under the continuous supervision of research team members, completed the data collection forms in faceto-face interviews with CHD patients. The face and content validity of the instrument was established by three experts in biostatistics as well as in research related to QoL.

\section{Ethics approval}

Approval to conduct the study was given by the An-Najah National University Institutional Review Board (IRB). Authorisation from the Palestinian health authorities was also obtained.

\section{Statistical analysis}

All analyses were accomplished using the Statistical Package for Social Sciences (SPSS, version 15). All data were presented as mean \pm standard deviation or median [interquartile range], or frequency (percentage), as appropriate. The patients were categorised into two groups using the median utility indexes (low or high) [26-28]. For EQ-5D index value and EQ-VAS, the HRQoL was considered high, if the index was $\geq$ median, and low, if the index was $<$ median. The normality of the data distribution was assessed by the Kolmogorov-Smirnov test. For the continuous variables the
Mann Whitney test was used, whereas for the categorical variables, Chi-square test was used. Additionally, Spearman's rank correlation coefficients were calculated. Multiple binary logistic regression analysis was carried out to evaluate the influence of demographic and medical characteristics, and self-efficacy factors on the QoL score. Multiple binary logistic regression analysis was used to identify factors associated with better HRQoL by including the factors, which were statistically significant in the univariate analysis. Statistical significance was set at $p<0.05$. Internal consistency for all scales was measured using Cronbach's alpha coefficient.

\section{Results}

Participant's characteristics

A total of 275 patients agreed to participate in the current study, giving a response rate of $97.17 \%$. The patients' mean age was $59.51 \pm 10.1$ years with a range of 29 and 90 years. As seen in Table 1, most were male (56\%), married (72\%), had village residency (49.1\%), were unemployed (53.1\%), had a low income $(57.8 \%)$, a primary level of education (38.5\%), and were nonsmokers (52.4\%). The mean duration of the disease was $4.09 \pm 3.80$. Thirteen $(4.7 \%)$ had no history of chronic diseases, 38 (13.8\%) had a history of one disease, $84(30.5 \%)$ had a history of two diseases, $73(26.5 \%)$ had a history of three diseases, and 67 (24.4\%) had a history of four or more diseases. Eighty-one (29.5\%), 161 (58.5\%), and 33 (12.0\%) were intending to use one to three, four to six, and more than six medications, respectively. The mean BMI was $28.78 \pm 4.03$.

\section{EQ-5D health status}

The number (\%) of patients who reported that there was no problem in each dimension of the five QoL dimensions 
Table 3 EQ-VAS by socio-demographic and clinical characteristics

\begin{tabular}{|c|c|c|c|c|}
\hline Variable & $\begin{array}{l}\text { Total } \\
\text { Frequency (\%) or median [Q1-Q3] } \\
N=275\end{array}$ & $\begin{array}{l}\text { Patients with better HRQoL } \\
\text { Frequency (\%) or median [Q1-Q3] } \\
n=148\end{array}$ & $\begin{array}{l}\text { Patients with worse HRQoL } \\
\text { Frequency (\%) or median [Q1-Q3] } \\
n=127\end{array}$ & $p$-value ${ }^{\text {a }}$ \\
\hline \multicolumn{5}{|l|}{ Age (year) } \\
\hline$<48$ & $28(10.2)$ & $23(15.5)$ & $5(3.9)$ & \multirow[t]{5}{*}{$0.008^{b}$} \\
\hline $48-57$ & $77(28.0)$ & $42(28.4)$ & $35(27.6)$ & \\
\hline $58-67$ & $114(41.5)$ & $60(40.5)$ & $54(42.5)$ & \\
\hline $68-77$ & 43(15.6) & $16(10.8)$ & $27(21.3)$ & \\
\hline$\geq 78$ & $13(4.7)$ & $7(4.7)$ & $6(4.7)$ & \\
\hline \multicolumn{5}{|l|}{ Gender } \\
\hline Female & $121(44.0)$ & $62(41.9)$ & $59(46.5)$ & \multirow[t]{2}{*}{$0.447^{b}$} \\
\hline Male & 154(56.0) & $86(58.1)$ & $68(53.5)$ & \\
\hline \multicolumn{5}{|l|}{ Residency } \\
\hline City & $108(39.3)$ & $57(38.5)$ & $51(40.2)$ & \multirow[t]{3}{*}{$0.819^{b}$} \\
\hline Village & 135(49.1) & $75(50.7)$ & $60(47.2)$ & \\
\hline Palestinian refugee camps & $32(11.6)$ & $16(10.8)$ & $16(12.6)$ & \\
\hline \multicolumn{5}{|l|}{ Social status } \\
\hline Married & 198(72.0) & $113(76.4)$ & $85(66.9)$ & \multirow[b]{2}{*}{$0.083^{b}$} \\
\hline Single, widowed, divorced & $77(28.0)$ & $35(23.6)$ & $42(33.1)$ & \\
\hline \multicolumn{5}{|l|}{ Educational level } \\
\hline No formal & $66(24.0)$ & $27(18.2)$ & $39(30.7)$ & \\
\hline Primary & 106(38.5) & $51(34.5)$ & $55(43.3)$ & \multirow[t]{3}{*}{$<0.001^{b}$} \\
\hline Secondary & $60(21.8)$ & $34(30.0)$ & $26(20.5)$ & \\
\hline University & 43(15.6) & $36(24.3)$ & $7(5.5)$ & \\
\hline \multicolumn{5}{|l|}{ Occupation } \\
\hline Employed & 129(46.9) & $88(59.5)$ & $41(32.3)$ & \multirow[t]{2}{*}{$<0.001^{b}$} \\
\hline Unemployed & $146(53.1)$ & $60(40.5)$ & $86(67.7)$ & \\
\hline \multicolumn{5}{|l|}{ Income (NIS) } \\
\hline Moderate to high & $116(42.2)$ & $79(53.4)$ & $37(29.1)$ & \multirow[t]{2}{*}{$<0.001^{b}$} \\
\hline Low & 159(57.8) & $69(46.6)$ & $90(70.9)$ & \\
\hline \multicolumn{5}{|l|}{ BMl } \\
\hline Normal & 49(17.8) & $24(16.2)$ & $25(19.7)$ & \multirow[t]{3}{*}{$0.570^{b}$} \\
\hline Overweight & 129(46.9) & $68(45.9)$ & $61(48.0)$ & \\
\hline Obese & $97(35.3)$ & $56(37.8)$ & $41(32.3)$ & \\
\hline \multicolumn{5}{|l|}{ Cigarette } \\
\hline Not smoker & 144(52.4) & $85(57.4)$ & $59(60.5)$ & \multirow[t]{5}{*}{$0.257^{b}$} \\
\hline Light & $7(2.5)$ & $4(2.7)$ & $3(2.4)$ & \\
\hline Moderate & $36(13.1)$ & $17(11.5)$ & $19(15.0)$ & \\
\hline Heavy & $13(4.7)$ & $4(2.7)$ & $9(7.1)$ & \\
\hline Ex-smoker & $75(27.3)$ & $38(25.7)$ & $37(29.1)$ & \\
\hline \multicolumn{5}{|l|}{ Duration of the disease (year) } \\
\hline$\leq 3$ & $139(50.5)$ & $86(58.1)$ & $53(41.7)$ & \\
\hline $4-5$ & $71(25.8)$ & $38(25.7)$ & $33(26 / 0)$ & \multirow[t]{2}{*}{$<0.001^{b}$} \\
\hline$>5$ & $65(23.6)$ & 24(16.2) & $41(32.3)$ & \\
\hline \multicolumn{5}{|l|}{ Total number of medications } \\
\hline $1-3$ & $81(29.5)$ & $47(31.8)$ & $34(26.8)$ & $0.055^{b}$ \\
\hline
\end{tabular}


Table 3 EQ-VAS by socio-demographic and clinical characteristics (Continued)

\begin{tabular}{|c|c|c|c|c|}
\hline Variable & $\begin{array}{l}\text { Total } \\
\text { Frequency (\%) or median [Q1-Q3] } \\
N=275\end{array}$ & $\begin{array}{l}\text { Patients with better HRQoL } \\
\text { Frequency (\%) or median [Q1-Q3] } \\
n=148\end{array}$ & $\begin{array}{l}\text { Patients with worse HRQoL } \\
\text { Frequency (\%) or median [Q1-Q3] } \\
n=127\end{array}$ & $p$-value ${ }^{a}$ \\
\hline $4-6$ & $161(58.5)$ & $78(52.7)$ & $83(65.4)$ & \\
\hline$\geq 7$ & $33(12.0)$ & $23(15.5)$ & $10(7.9)$ & \\
\hline \multicolumn{5}{|c|}{ Total number of chronic diseases } \\
\hline 0 & $13(4.7)$ & $11(7.4)$ & $2(1.6)$ & \\
\hline 1 & $38(13.8)$ & $22(14.9)$ & $16(12.6)$ & \multirow[t]{4}{*}{$0.070^{b}$} \\
\hline 2 & $84(30.5)$ & $37(25.0)$ & $47(37.0)$ & \\
\hline 3 & $73(26.5)$ & $41(27.7)$ & $32(25.2)$ & \\
\hline$\geq 4$ & $67(24.4)$ & $37(25.0)$ & $30(23.6)$ & \\
\hline PEPPI-5 & $17[15-20]$ & $18[16-20]$ & $16[14-19]$ & $0.002^{\mathrm{c}}$ \\
\hline SEMCD-6 & $5.8[5-6.8]$ & $6.1[5.3-6.8]$ & $5.5[4.8-6.8]$ & $0.005^{c}$ \\
\hline SCSES & $34[29-38]$ & $37[30-40]$ & $31[27-36]$ & $<0.001^{c}$ \\
\hline
\end{tabular}

was as follows: mobility 47 (17.1\%), self-care 158 (57.5\%), usual activities 68 (24.7\%), pain/discomfort 38 (13.8\%) and anxiety/depression 48 (17.5\%), as shown in Fig 1. A total of 97 health states were found, and $3(1.1 \%)$ participants reported that they had no problem in any QoL dimension.

\section{EQ-5D index values and EQ-VAS score}

The median and mean of the EQ-5D index value was 0.64 [interquartile range: 0.56-0.73], 0.62 (SD 0.16), respectively. The estimates of internal consistency (Cronbach's alpha) for the EQ-5D index was 0.755 , indicating acceptable internal consistency reliability. The median and mean of the EQ-VAS was 60.00 [interquartile range: 45.0070.00 ] and $57.44 \pm 1.61$, respectively. The cut-off for impaired HRQoL was 0.64 and 60 for EQ-5D index value and EQ-VAS, respectively. Of the 275 CHD patients, 140 (50.9\%) patients had high EQ-5D index value, and 148 (53.8\%) had high EQ-VAS score. Table 2 shows the significant differences between participants according to age, occupational status, duration of disease, total number of medications, total number of chronic diseases, PEPPI-5, SEMCD-6, and SCSES ( $p$-value< 0.05). No remarkable differences were noted between participants according to gender, residency, social status, educational level, income, BMI, or cigarette smoking.

Table 3 shows significant differences between participants according to age, educational level, occupation, income, duration of disease, PEPPI-5, SEMCD-6, and SCSES ( $p$-value <0.05). No significant differences were noted between CHD patients according to gender, residency, social status, cigarette smoking, BMI, total number of medications, or total number of chronic diseases.
A modest positive correlation was found between EQVAS and EQ-5D $(r=0.378, p$-value $<0.001)$.

\section{Self-efficacy scales}

The median of the PEPPI-5, SCSES and SEMCD-6 was 17.00 [interquartile range: 15.00-20.00], 34.00 [interquartile range: $29.00-38.00$ ], and 5.80 [interquartile range: 5.006.80], respectively. The estimates of internal consistency (Cronbach's alpha) for the PEPPI-5, SCSES and SEMCD-6 were $0.799,0.848$, and 0.865 , respectively, indicating acceptable to good internal consistency reliability.

\section{Univariate analysis}

The univariate analysis showed that age $(p=0.025)$, occupational status $(p=0.006)$, duration of disease $(p=$ $0.025)$, total number of medications $(p<0.001)$, total number of chronic diseases $(p<0.001)$, PEPPI-5 $(p<$ 0.001), SEMCD-6 $(p<0.001)$, and SCSES $(p<0.001)$ were significantly associated with better QoL (Table 2). Correlation tests revealed moderate positive associations between the QoL and the PEPPI-5 ( $r=0.419$; $p$-value < $0.001)$, SEMCD-6 $(r=0.419 ; p$-value $<0.001)$, and SCSES scores $(r=0.273$; $p$-value $<0.001)$; (Table 4$)$.

\section{Multiple logistic regression analysis}

Multiple binary logistic regression analysis, using the EQ5D-5 L index score (high versus low) as a dependent variable and the following factors as independent variables: covariates of age, employment status, duration of disease, number of medications, number of chronic diseases, PEPPI-5, SEMCD-6, and SCSES scores, showed that only patients with higher PEPPI-5 score (odds ratio $(\mathrm{OR})=$ $1.11 ; 95 \%$ confidence interval $(\mathrm{CI})=1.01-1.22 ; p=0.036)$, 
Table 4 Correlations with quality of life in coronary heart disease patients

\begin{tabular}{llllll}
\hline Scales & EQ-5D & & & EQ-VAS & \\
\cline { 2 - 3 } & $P$-value & Correlation & & $P$-value & Correlation \\
\hline PEPPI-5 & $<0.001$ & 0.419 & & $<0.001$ & 0.419 \\
Sullivan's scale & $<0.001$ & 0.524 & & $<0.001$ & 0.524 \\
SEMCD-6 & $<0.001$ & 0.273 & & $<0.001$ & 0.273 \\
EQ-5D & & & $<0.001$ & 0.378 \\
EQ-VAS & $<0.001$ & 0.378 & & \\
\hline
\end{tabular}

EQ-5D European Quality of Life scale 5 dimensions, EQ-VAS European Quality of Life visual analogue scale, PEPPI-5 Perceived Efficacy in Patient-Physician Interactions, SEM-CD Self-Efficacy for Managing Chronic Disease 6-Item Scale

and higher SCSES score $(\mathrm{OR}=1.10 ; 95 \% \mathrm{CI}=1.03-1.17$; $p=0.004$ ) were significantly associated with a high QoL score. Moreover, multiple binary logistic regression model showed that patients with higher numbers of medications $(\mathrm{OR}=0.23 ; 95 \% \mathrm{CI}=0.07-0.78) ; p=0.018)$ remained significantly associated with impaired QoL. The results of the multiple binary logistic regression model are summarised in Table 5.

\section{Discussion}

The main objective of this research was to assess patterns of CSE and QoL in CHD patients in Nablus,
Palestine. The EQ-5D and EQ-VAS scales were used to evaluate QoL. The SEMCD-6, SCSES and PEPPI-5 were used to assess CSE.

In our study, the mean EQ-5D score among the CHD patients was $0.62 \pm 0.16$, whereas the findings in Chinese, Slovenian and Swiss studies using the same instrument were $0.889 \pm 0.172$ [29], $0.60 \pm 0.19$ [30], $0.82 \pm 0.16$ [31], respectively. However, studies of hypertensive, end stage renal disease and diabetic patients in our country revealed the means of the EQ- $5 \mathrm{D}$ were $0.80 \pm 0.16$ [22], $0.44 \pm 0.37$ [24], $0.7 \pm 0.20$ [32], respectively.

Using univariate analysis, independent associations with high QoL scores tended to be found in employment patients; in patients with short duration of the disease; a low number of medications; a low number of co-morbidities; and high score in the PEPPI-5, SEMCD-6, and SCSES instruments. Multiple binary logistic regression model showed that only patients with lower numbers of medications, and higher PEPPI-5 and SCSES scores, were associated with high QoL. Our findings seem to be consistent with those of other studies that found an association between self-efficacy and QoL [7,33-35]. There are several patient behaviours that may affect the progress of chronic diseases, such as adherence to a healthy diet, medications and healthy lifestyle, and avoiding unhealthy activities such

Table 5 Patients characteristics associated with quality of life in multiple binary logistic regression model

\begin{tabular}{|c|c|c|c|c|c|c|}
\hline \multicolumn{2}{|l|}{ Variable } & \multirow[t]{2}{*}{ B } & \multirow[t]{2}{*}{ S.E. } & \multirow[t]{2}{*}{ Wald } & \multirow[t]{2}{*}{ Sig. } & \multirow{2}{*}{$\begin{array}{l}\text { Odds ratio with } 95 \% \mathrm{Cl} \\
\text { Ref. }\end{array}$} \\
\hline Age & $<48$ & & & & & \\
\hline & $48-57$ & -0.07 & 0.59 & 0.01 & 0.912 & $0.94(0.29-2.98)$ \\
\hline & $58-67$ & -0.10 & 0.60 & 0.03 & 0.875 & $0.91(0.28-2.95)$ \\
\hline & $68-77$ & -0.08 & 0.71 & 0.01 & 0.910 & $0.92(0.23-3.70)$ \\
\hline & $\geq 78$ & 1.64 & 0.99 & 2.75 & 0.097 & $5.16(0.74-35.93)$ \\
\hline \multirow[t]{2}{*}{ Occupation } & Unemployed & & & & & Ref. \\
\hline & Employed & 0.27 & 0.32 & 0.74 & 0.391 & $1.31(0.71-2.43)$ \\
\hline \multirow[t]{3}{*}{ Duration of disease (year) } & $\leq 3$ & & & & & Ref. \\
\hline & $4-5$ & -0.78 & 0.37 & 4.33 & 0.057 & $0.46(0.22-1.09)$ \\
\hline & $>5$ & -0.69 & 0.42 & 2.71 & 0.100 & $0.50(0.22-1.14)$ \\
\hline \multirow[t]{3}{*}{ Total number of medications } & $1-3$ & & & & & Ref. \\
\hline & $4-6$ & -0.63 & 0.40 & 2.48 & 0.115 & $0.54(0.25-1.17)$ \\
\hline & $\geq 7$ & -1.47 & 0.62 & 5.57 & 0.018 & $0.23(0.07-0.78)$ \\
\hline \multirow[t]{5}{*}{ Total number of chronic diseases } & 0 & & & & & Ref. \\
\hline & 1 & 0.18 & 0.96 & 0.04 & 0.853 & $1.19(0.18-7.77)$ \\
\hline & 2 & -0.91 & 0.91 & 1.00 & 0.317 & $0.40(0.07-2.39)$ \\
\hline & 3 & -0.37 & 0.94 & 0.16 & 0.691 & $0.69(0.11-4.33)$ \\
\hline & $\geq 4$ & -1.10 & 0.97 & 1.30 & 0.254 & $0.33(0.05-2.21)$ \\
\hline \multicolumn{2}{|l|}{ Patient-Physician Interactions score } & 0.10 & 0.05 & 4.41 & 0.036 & $1.11(1.01-1.22)$ \\
\hline \multicolumn{2}{|c|}{ Self-Efficacy for Managing Chronic Disease score } & 0.26 & 0.14 & 3.34 & 0.068 & $1.29(0.98-1.70)$ \\
\hline \multicolumn{2}{|l|}{ Cardiac Self-Efficacy score } & 0.09 & 0.03 & 8.51 & 0.004 & $1.10(1.03-1.17)$ \\
\hline
\end{tabular}

Cl confidence interval, $\beta$ coefficient of predictor variables, S.E standard error

${ }^{a}$ The bold values indicate $P<0.05$ 
as smoking and a sedentary lifestyle [2, 35]. Numerous studies have shown that psychological distress is one of the major risk factors that may contribute to the development of CHD, in addition to the well-known risk factors such as hypertension and obesity [2]. Furthermore, type 2 diabetes may act as a negative factor that results in a poor quality of life, worse prognosis and severe clinical complications in patients with stable and unstable CHD [36-40].

It is proposed that health outcomes of the treatment of any chronic disease are affected by the patient's beliefs in his or her capability to adhere to medications and follow a healthy lifestyle. It is this belief which actually affects their behaviours [35]; according to Bandura, if people lack the self-efficacy to do something, they will not do it in the best way even if they can do it very well [41].

A modest positive correlation between EQ-5D and EQVAS was found with means for each as follows: $0.62 \pm$ 0.16 and $57.44 \pm 1.61$, similar to those reported in a Slovenian study in which the EQ-5D and EQ-VAS were $0.60 \pm 0.19$ and $58.6 \pm 19.9$, respectively [30]. These findings are in line with those of previous Palestinian studies with different populations, such as those with diabetes [32], hypertension [25], or chronic kidney disease [24].

Our results found that young patient age was associated with a high QoL, which accords with previous studies $[29,42]$. This can be explained by the observation that older patients have a longer duration of the disease, more co-morbidity and are more vulnerable to fear and a sense of approaching death. In addition, unemployment was correlated with a low QoL, as demonstrated by previous studies [43, 44]; possible explanations are that occupation raises access to health care by providing health insurance, assures income, and increases patient self-confidence.

The domain of clinical factors (duration of the disease, number of co-morbidities and number of medications) had an impact on QoL. A long duration of the disease, and high numbers of co-morbidities and medications were associated with low QoL, as found in other studies [45].

This study's strengths lie in the following: (1) it is the first study conducted in Palestine to assess the effects of CSE on QoL in CHD patients, (2) the sample size is relatively large, making it possible to identify the different factors that affect CSE and QoL and the relationship between them in CHD patients; (3) we conducted our research on CHD patients who were referred to Al-Watani Hospital and Al-Najah National University Hospital; most CHD patients in Nablus city, and the villages and refugee camps around it, receive their inpatient care in these hospitals. Consequently, the results of this research can be generalised to the Nablus population; and (4) data collection was cost-efficient. However, we faced some limitations during the conduct of this research, as follows: (1) this is a cross-sectional study and it is therefore difficult to prove causal relationships between the scales and their associated factors; and (2) the results of this research cannot be generalised to the overall Palestinian population since data were collected only from the Nablus population.

\section{Conclusions}

The results of the study identified that lower levels of selfefficacy, poorer patient-physician interactions, and patients with high number of medications predicted lower HRQoL. Health providers should be aware of these factors in CHD patients when attempting to improve their QoL.

\section{Abbreviations}

BMI: Body mass index; CHD: Coronary artery disease; Cl: Confidence interval; CSE: Cardiac self-efficacy; EQ-5D-5 L: Five-level EuroQoL five-dimensional instrument; HRQoL: Health-related quality of life; IRB: Institutional review board; OR: Odds ratios; PEPPI-5: 5-item perceived efficacy in patient-physician interaction scale; Q1-Q2: Quartile 1 - quartile 3; QoL: Quality of life;

SCSES: Sullivan's cardiac self-efficacy scale; SD: Standard deviation; SEMCD6: Self- efficacy for managing chronic diseases 6-item scale

\section{Acknowledgements}

The authors would like to thank all of the patients who gave their time so generously to participate in the research. We also would like to thank the expert panel for their many contributions to help with this study.

\section{Authors' contributions}

$\mathrm{RI}$ and $\mathrm{AB}$ conducted the data collection, performed the analyses and literature search, and drafted the manuscript. SZ conceived the research idea, designed the study, led the data analysis and interpreted the data, participated in drafting the manuscript, and addressed the reviewers' comments. All authors read, and approved the final manuscript.

\section{Funding}

No funding was received in the preparation of this study.

\section{Availability of data and materials}

The datasets used and/or analysed during the current study are available from the corresponding author on reasonable request.

\section{Ethics approval and consent to participate}

Approval to conduct this study was granted by An-Najah National University Institutional Review Board before initiation of this study. Obtaining only verbal consent was approved by the ethics committee. Authorisation from the Palestinian health authorities was also obtained. Informed verbal consent was granted by all participants rather than written consent because the research did not involve any therapeutic intervention and the participations in the study were clearly below minimal risk. Verbal consent was obtained from the patients before starting data collection. The interviewer read the consent form in Arabic to each participant. When participants gave verbal consent to participate, a copy of the consent form attached to each form of data collection was marked by the interviewer.

\section{Consent for publication}

Not applicable.

\section{Competing interests}

The authors declare that they have no competing interests.

\section{Author details}

${ }^{1}$ Department of Medicine, College of Medicine and Health Sciences, An-Najah National University, Nablus 44839, Palestine. ${ }^{2}$ Poison Control and Drug Information Center (PCDIC), College of Medicine and Health Sciences, An-Najah National University, Nablus 44839, Palestine. ${ }^{3}$ Department of Clinical and Community Pharmacy, College of Medicine and Health Sciences, An-Najah National University, Nablus 44839, Palestine. ${ }^{4}$ Clinical Research Centre, An-Najah National University Hospital, Nablus 44839, Palestine. 
Received: 7 June 2019 Accepted: 27 November 2019 Published online: 13 December 2019

\section{References}

1. Song KJ. The effects of self-efficacy promoting cardiac rehabilitation program on self-efficacy, health behavior, and quality of life. Taehan Kanho Hakhoe Chi. 2003:33(4):510-8.

2. Allahverdipour $H$, Asgharijafarabadi M, Heshmati R, Hashemiparast M. Functional status, anxiety, cardiac self-efficacy, and health beliefs of patients with coronary heart disease. Health Promot Perspect. 2013;3(2):217-29.

3. Poortaghi S, Baghernia A, Golzari SE, Safayian A, Atri SB. The effect of homebased cardiac rehabilitation program on self efficacy of patients referred to cardiac rehabilitation center. BMC Res Notes. 2013;6:287.

4. Abu-Rmeileh NM, Shoaibi A, O'Flaherty M, Capewell S, Husseini A. Analysing falls in coronary heart disease mortality in the West Bank between 1998 and 2009. BMJ Open. 2012;2(4):e001061.

5. Ministry of Health. Health annual report palestine 2014. 2015. http://www. moh.ps/Content/Books/kD3bquHr7jbwK9f6VQJAsLDCuckgEDICZUFa9ssb62 m9Eim2le562D_ECDSNEboZRJwc6HyiggSMzKUPMeDJa2 vkBNIAdZOGIvNuS9CHKJjGO.pdf (Accessed March 11 2017).

6. Kark JD, Fink R, Adler B, Goldberger N, Goldman S. The incidence of coronary heart disease among Palestinians and Israelis in Jerusalem. Int Epidemiol. 2006;35(2):448-57

7. O'Neil A, Berk M, Davis J, Stafford L. Cardiac-self efficacy predicts adverse outcomes in coronary artery disease (CAD) patients. Health. 2013;05(07):6-14.

8. World Health Organization. WHOQOL: measuring quality of life. 2017. http:// www.who.int/healthinfo/survey/whoqol-qualityoflife/en/ (Accessed Feb 25 2017).

9. Saengsiri A-O, Thanasilp S, Preechawong S. Factors predicting quality of life for coronary artery disease patients after percutaneous coronary intervention. Asian Biomedicine. 2014;8(1):31-42

10. Jacobs JE. Quality of life: what does it mean for general practice? Br J Gen Pract. 2009;59(568):807-8.

11. Beng KS. The last hours and days of life: a biopsychosocial-spiritual model of care. Asia Pac Fam Med. 2004;4:1-3.

12. Daaleman TP, Elder GH Jr. Family medicine and the life course paradigm. J Am Board Fam Med. 2007;20(1):85-92

13. Go AS, Mozaffarian D, Roger VL, Benjamin EJ, Berry JD, Blaha MJ, Dai S, Ford ES, Fox CS, Franco S, et al. Heart disease and stroke statistics-2014 update: a report from the American Heart Association. Circulation. 2014;129(3):e28-e292.

14. Zachariah G, Harikrishnan S, Krishnan MN, Mohanan PP, Sanjay G, Venugopal K, Thankappan KR. Prevalence of coronary artery disease and coronary risk factors in Kerala, South India: a population survey - design and methods. Indian Heart J. 2013:65(3):243-9.

15. Suwatanaviroj T, Yamwong S. Prevalence of coronary artery disease in different ethnic groups at a tertiary care hospital. J Med Assoc Thail. 2013; 96(10):1298-301.

16. Heidenreich PA, Trogdon JG, Khavjou OA, Butler J, Dracup K, Ezekowitz MD, Finkelstein EA, Hong Y, Johnston SC, Khera A, et al. Forecasting the future of cardiovascular disease in the United States: a policy statement from the American Heart Association. Circulation. 2011;123(8):933-44.

17. Henselmans I, Heijmans M, Rademakers J, van Dulmen S. Participation of chronic patients in medical consultations: patients' perceived efficacy, barriers and interest in support. Health Expect. 2015;18(6):2375-88.

18. Stanford Patient Education Research Center. Evaluation tools. 2017. http:// patienteducation.stanford.edu/research/ (Accessed March 5 2017).

19. Fors A, Ulin K, Cliffordson C, Ekman I, Brink E. The cardiac self-efficacy scale, a useful tool with potential to evaluate person-centred care. Eur J Cardiovasc Nurs. 2015;14(6):536-43.

20. Herdman M, Gudex C, Lloyd A, Janssen M, Kind P, Parkin D, Bonsel G, Badia $X$. Development and preliminary testing of the new five-level version of EQ5D (EQ-5D-5L). Qual Life Res. 2011:20(10):1727-36.

21. EuroQol Group. EQ-5D-5L crosswalk index value calculator. 2015. http://www. eurogol.org/fileadmin/user_upload/Documenten/Excel/Crosswalk_5L/EQ-5D-5 L_Crosswalk_Index_Value_Calculator.v2.xls (Accessed March 15 2017).

22. Al-Jabi SW, Zyoud SH, Sweileh WM, Wildali AH, Saleem HM, Aysa HA, Badwan MA, Awang R. Relationship of treatment satisfaction to healthrelated quality of life: findings from a cross-sectional survey among hypertensive patients in Palestine. Health Expect. 2015;18(6):3336-48.

23. Zyoud SH, Al-Jabi SW, Sweileh WM, Wildali AH, Saleem HM, Aysa HA, Badwan MA, Awang R, Morisky DE. Health-related quality of life associated with treatment adherence in patients with hypertension: a cross-sectional study. Int J Cardiol. 2013;168(3):2981-3.

24. Zyoud SH, Daraghmeh DN, Mezyed DO, Khdeir RL, Sawafta MN, Ayaseh NA, Tabeeb GH, Sweileh WM, Awang R, Al-Jabi SW. Factors affecting quality of life in patients on haemodialysis: a cross-sectional study from Palestine. BMC Nephrol. 2016;17(1):44.

25. Al-Jabi SW, Zyoud SH, Sweileh WM, Wildali AH, Saleem HM, Aysa HA, Badwan MA, Awang R. Assessment of health-related quality of life among hypertensive patients: a cross-sectional study from Palestine. J Public Health 2014;22(3):277-86.

26. Zyoud SH, Awang R, Sulaiman SA, Al-Jabi SW. An analysis of the length of hospital stay after acetaminophen overdose. Hum Exp Toxicol. 2011;30(7):550-9.

27. Aga Z, Machina M, McCluskey SA. Greater intravenous fluid volumes are associated with prolonged recovery after colorectal surgery: a retrospective cohort study. Br J Anaesth. 2016;116(6):804-10.

28. Sallinen H, Sairanen T, Strbian D. Quality of life and depression 3 months after intracerebral hemorrhage. Brain Behav. 2019;9(5):e01270.

29. Wang L, Wu YQ, Tang X, Li N, He L, Cao Y, Chen DF, Hu YH. Profile and correlates of health-related quality of life in Chinese patients with coronary heart disease. Chin Med J. 2015;128(14):1853-61.

30. Tusek-Bunc K, Petek D. Comorbidities and characteristics of coronary heart disease patients: their impact on health-related quality of life. Health Qual Life Outcomes. 2016;14(1):159.

31. Gencer B, Rodondi N, Auer R, Nanchen D, Raber L, Klingenberg R, Pletscher M, Juni $P$, Windecker S, Matter CM, et al. Health utility indexes in patients with acute coronary syndromes. Open Heart. 2016;3(1):e000419.

32. Zyoud SH, Al-Jabi SW, Sweileh WM, Arandi DA, Dabeek SA, Esawi HH, Atyeh $\mathrm{RH}$, Abu-Ali HA, Sleet Yl, Abd-Alfatah BM, et al. Relationship of treatment satisfaction to health-related quality of life among Palestinian patients with type 2 diabetes mellitus: findings from a cross-sectional study. J Clin Transl Endocrinol. 2015;2(2):66-71.

33. Sarkar U, Ali S, Whooley MA. Self-efficacy and health status in patients with coronary heart disease: findings from the heart and soul study. Psychosom Med. 2007:69(4):306-12.

34. Brink E, Alsen P, Herlitz J, Kjellgren K, Cliffordson C. General self-efficacy and health-related quality of life after myocardial infarction. Psychol Health Med. 2012;17(3):346-55

35. Sarkar U, Ali S, Whooley MA. Self-efficacy as a marker of cardiac function and predictor of heart failure hospitalization and mortality in patients with stable coronary heart disease: findings from the heart and soul study. Health Psychol. 2009;28(2):166-73.

36. Sardu C, Paolisso P, Sacra C, Mauro C, Minicucci F, Portoghese M, Rizzo MR, Barbieri M, Sasso FC, D'Onofrio N, et al. Effects of metformin therapy on coronary endothelial dysfunction in patients with prediabetes with stable angina and nonobstructive coronary artery stenosis: the CODYCE multicenter prospective study. Diabetes Care. 2019;42(10):1946-55.

37. Marfella R, Sardu C, Calabro P, Siniscalchi M, Minicucci F, Signoriello G, Balestrieri ML, Mauro C, Rizzo MR, Paolisso G, et al. Non-ST-elevation myocardial infarction outcomes in patients with type 2 diabetes with nonobstructive coronary artery stenosis: effects of incretin treatment. Diabetes Obes Metab. 2018:20(3):723-9.

38. Marfella R, Sardu C, Balestrieri ML, Siniscalchi M, Minicucci F, Signoriello G, Calabro P, Mauro C, Pieretti G, Coppola A, et al. Effects of incretin treatment on cardiovascular outcomes in diabetic STEMI-patients with culprit obstructive and multivessel non obstructive-coronary-stenosis. Diabetol Metab Syndr. 2018;10:1.

39. Sasso FC, Pafundi PC, Marfella R, Calabro P, Piscione F, Furbatto F, Esposito G, Galiero R, Gragnano F, Rinaldi L, et al. Adiponectin and insulin resistance are related to restenosis and overall new $\mathrm{PCl}$ in subjects with normal glucose tolerance: the prospective AIRE study. Cardiovasc Diabetol. 2019;18(1):24.

40. Sardu C, D'Onofrio N, Torella M, Portoghese M, Loreni F, Mureddu S, Signoriello G, Scisciola L, Barbieri M, Rizzo MR, et al. Pericoronary fat inflammation and major adverse cardiac events (MACE) in prediabetic patients with acute myocardial infarction: effects of metformin. Cardiovasc Diabetol. 2019;18(1):126.

41. Bandura A. Self-efficacy: the exercise of control. New York: W H Freeman/ Times Books/ Henry Holt \& Co; 1997.

42. Sullivan PW, Lawrence WF, Ghushchyan V. A national catalog of preferencebased scores for chronic conditions in the United States. Med Care. 2005: 43(7):736-49. 
43. Ko HY, Lee JK, Shin JY, Jo E. Health-related quality of life and cardiovascular disease risk in Korean adults. Korean J Fam Med. 2015;36(6):349-56.

44. Jiang Y, Hesser JE. Associations between health-related quality of life and demographics and health risks. Results from Rhode Island's 2002 behavioral risk factor survey. Health Qual Life Outcomes. 2006;4(1):14.

45. Tuzun H, Aycan S, Ilhan MN. Impact of comorbidity and socioeconomic status on quality of life in patients with chronic diseases who attend primary health care centres. Cent Eur J Public Health. 2015;23(3):188-94.

\section{Publisher's Note}

Springer Nature remains neutral with regard to jurisdictional claims in published maps and institutional affiliations.

- fast, convenient online submission

- thorough peer review by experienced researchers in your field

- rapid publication on acceptance

- support for research data, including large and complex data types

- gold Open Access which fosters wider collaboration and increased citations

- maximum visibility for your research: over $100 \mathrm{M}$ website views per year

At $\mathrm{BMC}$, research is always in progress. 